\title{
PEMANFAATAN MEDIA WAYANG KERTAS UNTUK MENINGKATKAN MUTU PERKEMBANGAN KARAKTER BAHASA ANAK DALAM BERKOMUNIKASI VERBAL
}

\author{
Oleh \\ Natal Kristiono, Mutmainah \\ Universitas Negeri Semarang, TK Negeri Pembina Belik \\ natalkristiono@mail.unnes.ac.id, mutmainahpembina@gmail.com
}

Diterima 10 Juli 2018, direvisi 26 Juli 2018, diterbitkan 31 Agustus 2018

\begin{abstract}
Early childhood education itself is education aimed at preschool children with the aim that children can develop their potential from an early age so that they can develop naturally as children. Based on experience in TK Negeri Pembina Belik, Researchers found a problem in the language character of students, namely the lack of verbal communication between students with one another, children are still quiet and rarely communicate directly with their peers. The formulation of the problem to be studied in this study is the lack of communication activities among peers due to the lack of communication support media that attracts and motivates children to start a conversation or communication directly / verbally. The use of paper puppet media carried out in two cycles has a positive impact on several components of activities, especially for students. Children are more actively communicating, independent, fostering self-confidence, and strong curiosity. The application of this media can be carried out in various learning and development aspects.
\end{abstract}

Keywords: Wayang, character, early childhood

\section{PENDAHULUAN}

Taman kanak-kanak (TK) merupakan lembaga pendidikan formal sebelum anak memasuki sekolah dasar. Lembaga ini dianggap penting karena pada masa ini adalah masa yang disebut "Golden Age" (usia emas) yang didalamnya terdapat usia peka yang hanya datang sekali. Masa peka merupakan suatu masa yang menuntut perkembangan anak untuk dikembangakan secara optimal.
Pendidikan anak usia dini sendiri adalah pendidikan yang ditujukan bagi anak-anak usia prasekolah dengan tujuan agar anak dapat mengembangkan potensinya sejak dini sehingga mereka dapat berkembang secara wajar sebagai anak. Salah satu tujuan dari pendidikan anak usia dini adalah agar anak memperoleh rangsangan intelektual, sosial emosional, kemampuan berkomunikasi sesuai dengan tingkat usianya. Upaya perkembangan ini dapat dilakukan dengan berbagai macam 
cara termasuk penggunaan alat peraga wayang kertas sebagai media komunikasi anak.

Berdasarkan pengalaman di TK Negeri Pembina Belik, Peneliti menemukan adanya masalah karakter bahasa peserta didik yaitu kurangnya komunikasi verbal antara peserta didik satu dengan lainnya, anak masih pendiam dan jarang berkomunikasi langsung dengan teman sebayanya.

Dengan memberikan motifasi kepada anak melalui bermain menggunakan media wayang kertas, diharapkan anak mampu berkomunikasi dengan teman-temannya dan aktif dalam berbagai kegiatan. Dengan media wayang kertas ini penulis berupaya untuk menumbuhkan rasa percaya diri anak dan ketertarikan anak dalam memulai komunikasi langsung dengan teman sebayanya. Pembuatan media wayang ikan ini disesuaikan dengan karakteristik anak, perkembangan sosial emosional dan kemampuan berbahasa anak diusianya. Berdasarkan kondisi tersebut, mka penulis berupaya dengan melakukan Penelitian Tindakan Kelas dengan judul "Pemanfaatan Media Wayang Kertas Untuk Meningkatkan Perkembangan Karakter Bahasa Anak Dalam Komunikasi Verbal Pada Anak Kelompok A di TK Negeri Pembina Belik".

Pengadaan alat peraga / media pembelajaran di taman kanak-kanak merupakan salah satu usaha yang dilakukan dalam rangka meningkatkan mutu pendidikan. Alat peraga tersebut dibuat untuk membantu terciptanya suasana belajar yang sesuai dengan tingkat pencapaian perkembangan kelompok usia 4 - 6 tahun atau usia taman kanak-kanak. Naluri anak dalam meningkatkan kemampuannya selalu berdasarkan unsur bermain. Oleh karena itu guru dituntut menyediakan sarana berupa alat peraga / media pembelajaran yang bersifat edukatif yang sesuai dengan kebutuhan dan sesuai dengan minat anak sehingga dapat menunjang proses belajar mengajar.

Alat peraga / media pembelajaran disamping alat-alat bermain yang sudah ada di TK, guru juga harus dapat membuat alat peraga / media pembelajaran dari bahan- bahan yang ada di lingkungan atau memodifikasi alat permainan yang sudah ada.

Dalam rangka belajar mengajar diusahakan agar penggunaan alat peraga/media pembelajaran tersebut dapat digunakan secara kreatif dan dapat memanfaatkan lingkungan sekitarnya untuk dikembangkan dan dimanfaatkan dalam pembelajaran.

Rumusan masalah yang akan dikaji dalam penelitian ini yaitu kurangnya aktifitas komunikasi antar teman sebaya dikarenakan tidak adanya media pendukung komunikasi yang menarik dan memotivasi anak untuk memulai sebuah percakapan atau komunikasi secara langsung/verbal.

Masalah tersebut akan dipecahkan melalui pemanfaatan media wayang kertas, yang anak-anak buat sendiri dan akan digunakan dengan menerapkan metode pembelajaran demonstrasi dan pemberian tugas.

\section{METODE}

Mengingat penelitian ini merupakan penelitian tindakan kelas, maka permasalahan yang dikaji akan dipecahkan melalui pemanfaatan media wayang kertas, yang anak-anak buat sendiri dan akan digunakan dengan menerapkan metode pembelajaran demonstrasi dan pemberian tugas. Penulis menggunakan prosedur pelaksanaan penelitian observasi dan refleksi dalam setiap siklus. Kegiatan itu terbagi dalam dua siklus.

\section{HASIL DAN PEMBAHASAN \\ Hasil}

Penelitian ini dilakukan dalam dua siklus, yaitu siklus I dan siklus II. Berikut prosedur kegiatan yang akan dilakukan pada tiap siklus.

\section{Siklus I}

Penelitian ini dilakukan pada anak kelompok A di TK Negeri Pembina Belik yang berjumlah 16 anak. Penelitian dilaksanakan pada awal tahun ajaran yaitu semester 1 pada minggu ke 5 .

a. Perencanaan Kegiatan

Sebelum pelaksanaan kegiatan dimulai, hal yang paling utama dilakukan adalah membuat perencanaan kegiatan selama 
satu siklus. Langkah-langkah yang dilakukan dalam menyiapkan pembelajaran satu siklus yaitu membuat rencana pelaksanaan pembelajaran harian, merencanakan pegelolaan kelas, merencanakan langkah-langkah perbaikan, menyiapkan alat dan bahan yang akan digunakan dalam pembelajaran. Dalam kegiatan ini alat dan bahan yang harus disiapkan antara lain piring kertas, potongan kepala ikan, ekor, sirip dan mata, lem kastol, stick es krim, solatip, kertas berwarna, spidol, gunting,lap tangan / tisu kering

b. Pelaksanaan Kegiatan

1) Kegiatan Awal \pm 30 menit

- Anak berbaris di halaman, mengucap ikrar dan do'a masuk kelas, mengucap salam dan guru menjawab salam.

- Kegiatan circle time.

- Penjelasan kegiatan oleh guru dan pembagian kelompok kegiatan sesuai minat anak.

2) Kegiatan Inti \pm 60 menit

- Anak berfokus pada kelompok bahasa.

- Guru menjelaskan alat dan bahan apa saja yang akan digunakan untuk kegiatan hari ini.

- Guru mendemonstrasikan cara membuat wayang kertas dan cara memainkannya. Kali ini yang dibuat adalah wayang ikan. Bahan yang akan digunakan dibersihkan dengan lap/tisu. Ambil dua piring kertas yang akan digunakan untuk badan ikan, kaitkan dengan solatip sampai membentuk badan ikan buntal. Selipkan stik es krim ke dalam badan ikan yang sudah dibuat. Ambil bagian kepala, sirip, ekor dan mata ikan yang sudah disiapkan oleh guru, tebali bagian tepinya dengan spidol hitam untuk memberi batas dan mempercantik wayang ikannya. Tempelkan semua bagian ikan pada badan ikan. Hiasi dengan guntingan kertas berwarna. Setelah jadi, anakanak bisa memainkan wayang tersebut.

- Pemberian tugas untuk setiap anak maju satu persatu dan memperlihatkan karyanya, memainkan wayang dengan bahasanya sendiri.

- Wayang dimainkan oleh satu anak/lebih dari satu anak.

- Setiap anak memegang satu wayang kertas ikan.

- $\quad$ Anak menggunakan wayang kertas ikan untuk bercerita dengan satu temannya. Posisi anak saling berhadapan, dan bermain layaknya dalang.

- Anak mulai bercerita/berkomunikasi menggunakan wayang kertas ikan dengan bahasa sendiri.

- Anak bebas menggunakan wayang kertas ikan misal untuk bercerita/berkomunikasi dengan temannya.

- Wayang kertas ikan dapat digunakan didalam kelas atau pada saat istirahat.

3) Istirahat \pm 30 menit

- Cuci tangan, membaca do'a Sebelum makan, makan bekal, membaca do'a sesudah makan.

- Anak-anak bermain di luar kelas di bawah pengawasan guru.

4) Kegiatan Akhir \pm 30 menit

- Bermain tepuk dan bernyanyi bersama.

- Mengulas kegiatan sehari.

- Berdo'a mau pulang dan mengucap salam dan guru menjawab salam.

c. Evaluasi

Guru mengevaluasi kegiatan anak pada siklus satu dan memberikan penilaian proses dan hasil pada pra siklus dan hasil siklus I. Hasil evaluasi pra siklus dan siklus I dapat dilihat pada tabel berikut : 
Tabel 1. Hasil Evaluasi Pra Siklus

\begin{tabular}{|c|l|c|c|}
\hline No & Nama Anak & Keaktifan dalam kegiatan komunikasi & Ket \\
\hline 1 & Abim & $\star$ & BB \\
\hline 2 & Aina & $\star$ & BB \\
\hline 3 & Arthur & $\star \star$ & BB \\
\hline 4 & Caca & $\star$ & MB \\
\hline 5 & Dea & $\star \star$ & BB \\
\hline 6 & Dyana & $\star$ & MB \\
\hline 7 & Farhan & $\star$ & BB \\
\hline 8 & Hegar & $\star$ & BB \\
\hline 9 & Nafisa & $\star$ & BB \\
\hline 10 & Nata & $\star$ & BB \\
\hline 11 & Nizam & $\star$ & BB \\
\hline 12 & Putra & $\star \star$ & BB \\
\hline 13 & Rangga & $\star$ & BB \\
\hline 14 & Tian & $32 \%$ & MB \\
\hline 15 & Varo & & BB \\
\hline 16 & Zaen & $\star$ & \\
\hline \multicolumn{2}{|c|}{ Prosentase } & $\star$ & \\
\hline
\end{tabular}

Keterangan :

BB : Belum Berkembang

MB : Mulai Berkembang

BSH : Berkembang Sesuai Harapan

BSB : Berkembang Sangat Baik

Tabel 2. Hasil Evaluasi Siklus 1

\begin{tabular}{|c|c|c|c|}
\hline No & Nama Anak & Keaktifan dalam kegiatan komunikasi & Ket \\
\hline 1 & Abim & $\star \star$ & $\mathrm{MB}$ \\
\hline 2 & Aina & $\star \star$ & MB \\
\hline 3 & Arthur & $\star \star$ & $\mathrm{MB}$ \\
\hline 4 & Caca & $\star \star \star$ & $\mathrm{BSH}$ \\
\hline 5 & Dea & $\star \star$ & MB \\
\hline 6 & Dyana & $\star \star \star$ & $\mathrm{BSH}$ \\
\hline 7 & Farhan & $\star \star$ & $\mathrm{MB}$ \\
\hline 8 & Hegar & $\star$ & $\mathrm{BB}$ \\
\hline 9 & Nafisa & $\star \star$ & $\mathrm{MB}$ \\
\hline 10 & Nata & $\star$ & $\mathrm{BB}$ \\
\hline 11 & Nizam & $\star \star \star$ & $\mathrm{BSH}$ \\
\hline 12 & Putra & $\star \star \star$ & $\mathrm{BSH}$ \\
\hline 13 & Rangga & $\star \star$ & $\mathrm{MB}$ \\
\hline 14 & Tian & $\star \star$ & $\mathrm{MB}$ \\
\hline 15 & Varo & $\star \star \star$ & $\mathrm{BSH}$ \\
\hline 16 & Zaen & $\star \star$ & $\mathrm{MB}$ \\
\hline & Prosentase & $55 \%$ & \\
\hline
\end{tabular}

Keterangan :

BB : Belum Berkembang

MB : Mulai Berkembang 
d. Tindak Lanjut

Berdasarkan hasil pelaksanaan siklus 1, terlihat adanya peningkatan keaktifan anak dalam kegiatan komunikasi dan kerjasama dengan teman sebaya. Masih ada beberapa anak yang belum bisa mengikuti kegiatan dengan baik dan belum aktif berkomunikasi langsung dengan teman sebayanya. Untuk itu penelitian dilanjutkan ke siklus 2 dengan metode yang sama dan media yang sama, namun dalam pelaksanaan kegiatan akan meningkatkan intensitas kerjasama antar teman, sehingga tercipta komunikasi yang lebih banyak lagi.

\section{Siklus 2}

a. Perencanaan Kegiatan

Rencana kegiatan siklus 2 sama dengan rencana kegiatan pada siklus 1 . Sebelum pelaksanaan kegiatan dimulai, siapkan alat dan bahan, pengkondisian kelas dan setting area main untuk kegiatan siklus 2 .

Pada siklus 1 anak bermain wayang dengan satu anak, di siklus 2 ini anak bermain dengan berkelompok 4 sampai 5 anak. Dalam kegiatan ini alat dan bahan yang harus disiapkan antara lain Piring kertas, Potongan bagian-bagian muka, Lem kastol, Stick es krim, Solatip, Kertas lipat warna hitam , Spidol, Gunting, Lap tangan / tisu kering

b. Pelaksanaan Kegiatan

1) Kegiatan Awal \pm 30 menit

- Anak berbaris di halaman, mengucap ikrar dan do'a masuk kelas, mengucap salam dan guru menjawab salam.

- Kegiatan circle time.

- Penjelasan kegiatan oleh guru dan pembagian kelompok kegiatan sesuai minat anak.

2) Kegiatan Inti \pm 60 menit

- Anak terbagi dalam 3 kelompok.

- Guru menjelaskan alat dan bahan apa saja yang akan digunakan untuk kegiatan hari ini.

- Guru mendemonstrasikan cara membuat wayang kertas dan cara memainkannya. Kali ini yang dibuat adalah wayang ekspresi wajah. Satu anak membuat satu wayang berbentuk ekspresi wajah yang mereka sukai, guru membuat contoh aneka ekspresi wajah dan anak memilih ekpresi mana yang disukai. Bahan yang akan digunakan dibersihkan dengan lap/tisu. Ambil dua piring kertas yang akan digunakan untuk muka, kaitkan dengan solatip sampai membentuk muka bulat. Selipkan stik es krim ke dalam piring kertas yang sudah dikaitkan tadi. Ambil bagian-bagian muka seperti mata, hidung, mulut/bibir yang sudah disiapkan oleh guru. Tempelkan semua bagian pada muka tadi. Hiasi dengan kertas lipat warna hitam yang dibentuk menyerupai rambut. Setelah jadi, anak-anak bisa memainkan wayang tersebut.

- Pemberian tugas untuk setiap anak maju satu persatu dan memperlihatkan karyanya, memainkan wayang dengan bahasanya sendiri.

- Wayang dimainkan oleh satu kelompok terdiri dari 4-5 anak.

- Setiap anak memegang satu wayang kertas.

- Anak menggunakan wayang kertas untuk bercerita dengan kelompoknya. Posisi anak melingkar dan mulai bermain percakapan yang dibuat oleh anak itu sendiri dengan bimbingan guru.

- Anak mulai bercerita/berkomunikasi menggunakan wayang kertas dengan bahasa sendiri.

- Anak bebas menggunakan wayang kertas misal untuk bercerita/berkomunikasi dengan temannya dan juga untuk kegiatan perkembangan lainnya seperti menghitung jumlah wayang, 
menyebutkan warna pada masingmasing wayang, menyebutkan bentuk geometri yang digunakan untuk pembuatan wayang.

- Wayang kertas dapat digunakan didalam kelas atau pada saat istirahat.

3) Istirahat \pm 30 menit

- Cuci tangan, membaca do'a Sebelum makan, makan bekal, membaca do'a sesudah makan.

- Anak-anak bermain di luar kelas di bawah pengawasan guru.
4) Kegiatan Akhir \pm 30 menit

- Bermain tepuk dan bernyanyi bersama.

- Mengulas kegiatan sehari.

- Berdo'a mau pulang dan mengucap salam dan guru menjawab salam.

c. Evaluasi

Guru mengevaluasi kegiatan anak pada siklus II dan memberikan penilaian proses dan hasil. Hasil evaluasi siklus II dapat dilihat pada tabel berikut :

Tabel 3. Hasil Evaluasi Siklus II

\begin{tabular}{|c|l|c|c|}
\hline No & Nama Anak & Keaktifan dalam kegiatan komunikasi & Ket \\
\hline 1 & Abim & $\star \star \star$ & BSH \\
\hline 2 & Aina & $\star \star \star$ & BSH \\
\hline 3 & Arthur & $\star \star \star$ & BSH \\
\hline 4 & Caca & $\star \star \star$ & BSB \\
\hline 5 & Dea & $\star \star \star \star$ & BSH \\
\hline 6 & Dyana & $\star \star \star$ & BSB \\
\hline 7 & Farhan & $\star \star \star$ & BSH \\
\hline 8 & Hegar & $\star \star \star$ & BSH \\
\hline 9 & Nafisa & $\star \star \star \star$ & BSH \\
\hline 10 & Nata & $\star \star \star \star$ & BSH \\
\hline 11 & Nizam & $\star \star \star$ & BSB \\
\hline 12 & Putra & $\star \star \star \star$ & BSB \\
\hline 13 & Rangga & $\star \star \star$ & BSH \\
\hline 14 & Tian & $85 \%$ & BSH \\
\hline 15 & Varo & & BSH \\
\hline 16 & Zaen & & \\
\hline \multicolumn{3}{|c|}{ Prosentase } &
\end{tabular}

Keterangan :

$\begin{array}{ll}\text { BB } & \text { : Belum Berkembang } \\ \text { MB } & \text { : Mulai Berkembang } \\ \text { BSH } & \text { : Berkembang Sesuai Harapan } \\ \text { BSB } & \text { : Berkembang Sangat Baik }\end{array}$

d. Tindak Lanjut

Berdasarkan hasil pelaksanaan siklus 2, terlihat adanya peningkatan keaktifan anak dalam kegiatan komunikasi dan kerjasama dengan teman sebaya mencapai prosentase $85 \%$. Pemanfaatan media wayang kertas yang anak buat sendiri bersama guru, dapat meningkatkan perkembangan bahasa anak dalam berkomunikasi langsung dengan teman dan guru. Penggunaan wayang kertas ini juga dapat digunakan dalam berbagai aspek perkembangan lain seperti nilai agama dan moral, motorik halus, bahasa, kognitif dan sosial emosional.

\section{Pembahasan \\ Dampak Kegiatan}


Pemanfaatan media wayang kertas yang dilakukan dalam 2 siklus memberi dampak positif pada beberapa komponen kegiatan terutama pada peserta didik. Anak lebih aktif berkomunikasi, mandiri, menumbuhkan rasa percaya diri, dan rasa ingin tahu yang kuat. Dampak positif juga terlihat dari pendidik yang selalu menciptakan berbagai inovasi pembelajaran terkait dengan media pembelajaran yang digunakan dalam setiap aspek perkembangan.

Secara kelembagaan TK Negeri Pembina Belik memiliki prestasi yang baik dalam berbagai perlombaan terkait dengan perkembangan bahasa anak, misal dalam lomba dongeng dan bercerita dengan media boneka jari. Prestasi yang diraih berdampak pada penilaian masyarakat akan keunggulan dan kualitas TK Negeri Pembina Belik.

Pemanfaatan media wayang kertas ini juga berdampak pada lingkup perkembangan lainnya seperti :

a) Lingkup perkembangan nilai-nilai moral dan agama.

- Menyebutkan/mengenal ciptaan Tuhan.

b) Lingkup perkembangan motorik halus.

- Melatih kelenturan otot jari-jari tangaMelatih koordinasi mata dengan tangan.

c) Lingkup perkembangan karakter bahasa.

- Mengembangkan imajinasi dalam bercerita/berkomunikasi.

- Mengolah kata dalam bercerita/berkomunikasi.

- Menumbuhkan minat anak dalam bercerita/berkomunikasi.

d) Lingkup perkembangan kognitif.

- Mengenal warna.

- Menghitung angka 1-10.

- Mengenal bentuk geometri.

e) Lingkup perkembangan sosial emosional.

- Meningkatkan rasa percaya diri.

- Menghargai hasil karya sendiri dan orang lain.

- Bekerjasama dan berbagi dalam kelompok dalam membuat wayang kertas.

\section{Faktor Pendukung}

Adapun faktor yang mendukung terlaksananya penerapan media pembelajaran wayang kertas pada anak kelompok A di TK Negeri Pembina Belik terbagi dalam dua kategori, yaitu :

1. Faktor internal

Faktor internal yang mendukung penerapan media pembelajaran ini antara lain dari peserta didik itu sendiri sangat antusias mengikuti kegiatan pembelajaran dari awal sampai akhir, rasa ingin tahu anak yang sangat tinggi sehingga anak merasa betah dan tidak bosan dalam mengikuti kegiatan. Anak dapar berimajinasi dengan media wayang tersebut, dengan bahasanya sendiri dan dimengerti oleh temantemannya. Tenaga pendidik dan kependidikan yang ada di TK Negeri Pembina juga memberi dukungan moril yang sangat berarti bagi terlaksananya penerapan media pembelajaran ini pada legiatan belajar mengajar di TK Negeri Pembina Belik. Sarana prasarana di TK Negeri Pembina Belik cukup memadai untuk terlaksananya penerapan media pembelajaran wayang kertas ini.

2. Faktor eksternal

Faktor pendukung lainnya datang dari masyarakat dan lingkungan TK Negeri Pembina Belik. Dukungan wali murid dan penyelenggara (komite) sekolah juga memberi peran dalam terlaksananya kegiatan pembelajaran dengan media wayang kertas ini.

\section{Alternatif Pengembangan}

Dalam upaya peningkatan perkembangan karakter bahasa anak, ada beberapa hal yang dapat dilakukan selain dari pemanfaatan wayang kertas berbentuk karakter. Rencana kegiatan selanjutnya untuk perkembangan bahasa anak dalam berkomunikasi antara lain

1. Penggunaan metode dongeng dalam pembelajaran dengan media panggung boneka 
2. Pemanfaatan boneka jari dalam peningkatan komunikasi anak

3. Memaksimalkan penggunaan kartu kata, kartu gambar dan seri buku cerita anak dalam perkembangan bahasa.

4. Menciptakan permainan baru dengan media pembelajaran inovatif lainnya.

\section{SIMPULAN}

Melalui pemanfaatan media wayang kertas dapat meningkatkan kemampuan bahasa terutama dalam berkomunikasi secara langsung (verbal) pada anak kelompok A di TK Negeri Pembina Belik. Penelitian dilaksanakan di TK Negeri Pembina Belik dengan tujuan untuk perbaikan pembelajaran di TK negeri Pemaina Belik, yang tujuan utamanya adalah meningkatkan perkembangan bahasa anak dalam berkomunikasi langsung melalui tahapantahapan dalam PTK

Kemampuan anak kelompok A TK Negeri Pembina Belik dalam berkomunikasi secara langsung dengan guru dan teman sebaya sudah cukup optimal/baik sesuai dengan yang diharapkan, dan sesuai tingkat perkembangan anak.

Penerapan media ini dapat dilaksanakan dalam berbagai pembelajaran dan aspek perkembangan. Segala sesuatu yang diperoleh selama kegiatan PTK yang sekiranya dapat meningkatkan kemampuan anak, dapat disampaikan kepada teman-teman sejawat atau Kelompok Kerja Guru (KKG). Sehingga teman yang lain mendapatkan masukan terhadap strategi mengajarnya. Sasaran pembelajaran dengan media wayang kertas bukan hanya pada anak kelompok A saja, tetapi juga dapat diterapkan padapembalajaran di kelompok B dengan inovasi pembelajaran sesuai tingkat usia anak.

\section{DAFTAR PUSTAKA}

Arsyad, A. (1997) Media Pengajaran, Jakarta: PT Raja Grafindo Persada

Depdikbud (1992). Pedoman Penggunaan Alat Peraga Taman Kanak-kanak, Jakarta: Depdikbud.

Depdikbud (1994). Program Kegiatan Belajar Taman Kanak-kanak, Jakarta: Depdikbud

Depdikbud, Ditjen Dikdasmen. (1997). Petunjuk Pembuatan dan Pemanfaatan Media Pendidikan, Jakarta: Direktorat Sarana Pendidikan

Depdikbud. (1999). Program Kegiatan Belajar Taman Kanak-kanak, Jakarta: Depdikbud

Dindikpora. (2010). Advokasi Kurikulum Taman kanak-kanak, Pemalang: 2010

Kristiono, N. (2017). PENGUATAN IDEOLOGI PANCASILA DI KALANGAN MAHASISWA UNIVERSITAS NEGERI SEMARANG. Harmony, 2(2), 193-204. Ngatmo, Y. (2003). Media Pembelajaran, Solo: Universitas Sebelas Maret 